\title{
Temperature response to the June 2020 solar eclipse observed by FORMOSAT-7/COSMIC2 in the Tibet sector
}

\author{
Yang-Yi Sun*, Chieh-Hung Chen, Tao Yu, Jin Wang, Lihui Qiu, Yifan Qi and Kai Lin
}

\begin{abstract}
This study explores the response of atmospheric temperature to the annular solar eclipse at the summer solstice on 21 June 2020. The radio occultation (RO) technique of the FORMOSAT-7/COSMIC2 (F7/C2) mission observes the temperature in the troposphere and stratosphere. The RO observations show that the temperature decreases significantly (near 4 to $8^{\circ} \mathrm{C}$ ) between 5 and $8 \mathrm{~km}$ altitudes over the Tibetan Plateau area within the $80 \%$ obscuration during the eclipse. The tropopause temperature increases by $\sim 2$ to $5^{\circ} \mathrm{C}$ over the same area. By contrast, the tropopause temperature decreases by $\sim 4^{\circ}$ to $5^{\circ} \mathrm{C}$ over the Indian Ocean. The F7/C2 RO technique captured not only the sudden tropospheric cooling and stratospheric warming over Tibet during the eclipse but also the possible response over the Indian Ocean away from the greatest eclipse.
\end{abstract}

\section{Key points}

1. RO temperature decreases over the Tibetan Plateau during the eclipse

2. Opposite changes of the tropopause temperatures over Tibet and Indian Ocean

3. Indian summer monsoon circulation was perturbed during the eclipse

Keywords: FORMOSAT-7/COSMIC-2, Radio occultation, Solar eclipse, Tibetan Plateau, Indian monsoon circulation

\section{Introduction}

As the Moon is in a position where it blocks the light from the Sun, the quick onset of the darkness induces a sudden drop in temperature of the air and generates local circulation near the Earth's surface (Clayton 1901; Aplin et al. 2016; Clark et al. 2016; Eugster et al. 2017; Turner et al. 2018; Mahmood et al. 2020). Wang and Liu (2010) first examined the FORMOSAT-3/COSMIC (Constellation Observing System for Meteorology, Ionosphere, and Climate) radio occultation (RO) temperature profiles during the 22 July 2009 total solar eclipse and found that

*Correspondence: sunyy@cug.edu.cn

Institute of Geophysics and Geomatics, China University of Geoscience, Wuhan, Hubei, China atmospheric response to the solar eclipse is not as simple as a cooling of the whole atmosphere. The reduction in solar heating results in the cooling in the troposphere near the surface, which is thermally driven. The thermal contraction in the troposphere can induce warming in the upper troposphere and lower stratosphere (between 13 and $23 \mathrm{~km}$ altitudes), which is dynamically driven. Wang et al. (2012) further examined the response of the RO temperature to the solar eclipses on 15 January 2010, 26 January 2009, 1 August 2008, and 22 September 2006. The results suggested that the characteristic stratosphere-troposphere coupling in the RO temperature profiles represent distinctive atmospheric responses to the solar eclipses.

\section{Springer}

(c) The Author(s) 2022. Open Access This article is licensed under a Creative Commons Attribution 4.0 International License, which permits use, sharing, adaptation, distribution and reproduction in any medium or format, as long as you give appropriate credit to the original author(s) and the source, provide a link to the Creative Commons licence, and indicate if changes were made. The images or other third party material in this article are included in the article's Creative Commons licence, unless indicated otherwise in a credit line to the material. If material is not included in the article's Creative Commons licence and your intended use is not permitted by statutory regulation or exceeds the permitted use, you will need to obtain permission directly from the copyright holder. To view a copy of this licence, visit http://creativecommons.org/licenses/by/4.0/. 
An annular solar eclipse nicknamed the "ring of fire" was visible in Africa and Asia at the summer solstice on 21 June 2020. The moon shadow appears over Africa near $0500 \mathrm{UT}$ and disappears over the Pacific Ocean near 0830 UT (https://eclipse.gsfc.nasa.gov/). It is another rare opportunity for us to examine the response of the atmosphere to transient obscuration. A solar eclipse is a unique and rare phenomenon that occurs over a particular area at a certain local time in a specific season. This eclipse is the only case occurring over Tibet near noon time in recent decades.

FORMOSAT-7/COSMIC2 (F7/C2) is the follow-on mission of FORMOSAT-3/COSMIC (F3/C). The RO technique onboard the satellite constellation of the F7/ $\mathrm{C} 2$ mission vertically scans the atmosphere mainly within $\pm 40^{\circ} \mathrm{N}$ (Schreiner et al. 2020; Lin et al. 2020; Chen et al. 2021a, b). The RO temperature profiles analyzed in this study are obtained from the post-processed wetPf2 product (ftp://tacc.cwb.gov.tw/fs7_pp_tdpc/level2/).

\section{Results}

Figure 1a displays that the $\mathrm{F} 7 / \mathrm{C} 2 \mathrm{RO}$ recorded twelve temperature profiles within and near the $80 \%$ obscuration area in the Tibetan Plateau longitudinal sector $\left(75^{\circ}\right.$ to $100^{\circ} \mathrm{E}$ ) from $05: 00$ to $10: 00 \mathrm{UT}$. Figure $1 \mathrm{~b}$ shows the temperature profiles within the areas of $20^{\circ}$ to $28^{\circ} \mathrm{N}$ (over North India), $28^{\circ}$ to $35^{\circ} \mathrm{N}$ (over the Tibetan Plateau area and within the $80 \%$ obscuration), $35^{\circ}$ to $40^{\circ} \mathrm{N}$ (beyond Tibet). The temperatures below $10 \mathrm{~km}$ over Tibet are lower than those over North India. By contrast, temperature near the tropopause over Tibet is higher than that over India. In this study, tropopause is defined as the minimum temperature of the vertical temperature profile. The average of the temperature within the entire path (from Africa to Pacific Ocean longitudes) of $80 \%$ obscuration did not change prominently during the eclipse (not shown here). The temperature changes occurred mainly over the Tibetan sector.

Figure 2 is the comparison of the temperature profiles during the eclipse period and the reference that is the average of the profiles collected over the three areas during seven days before and after the eclipse day (two weeks in total). Figure $2 \mathrm{a}$ and $\mathrm{b}$ display no significant change in temperature over North India. However, Fig. 2c-d illustrate the temperature changes over the Tibetan Plateau area within the $80 \%$ obscuration. Figure $2 \mathrm{~d}$ shows that the temperature decreases by $\sim 4$ to $8{ }^{\circ} \mathrm{C}$ between 5 and $8 \mathrm{~km}$. By contrast, the temperature increases by $\sim 2^{\circ}$ to $5{ }^{\circ} \mathrm{C}$ near the tropopause. In Fig. 2e and f, the two temperature profiles recorded over the northern side $\left(35^{\circ}\right.$ to $40^{\circ} \mathrm{N}$ ) of Tibet yield the similar changes as those between $28^{\circ}$ and $35^{\circ} \mathrm{N}$. Sun et al. (2014) examined the F3/C RO soundings and showed that the latitudinal variation in
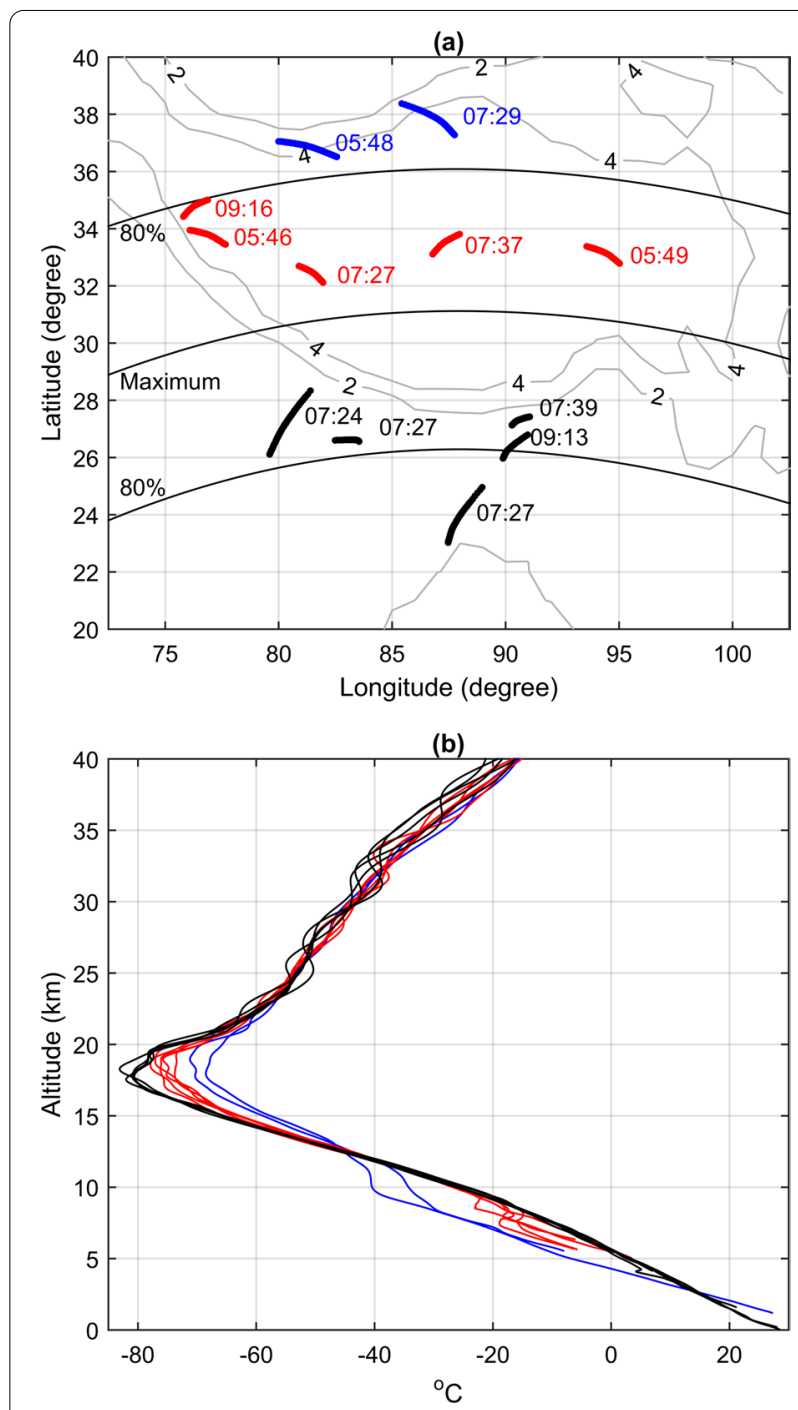

Fig. 1 a Spatial distribution of the FORMOSAT-7/COSMIC2 (F7/C2) radio occultation $(\mathrm{RO})$ temperature sounding profiles in the Tibetan Plateau longitudinal sector $\left(75^{\circ}\right.$ to $100^{\circ} \mathrm{E}$ ) from 05:00 to 10:00 UT on 21 June 2020. The gray curves sketch the topography. The black curves indicate the path of the $80 \%$ obscuration. $\mathbf{b}$ The black, red, and blue lines are, respectively, the RO temperature profiles over the areas of North India $\left(20^{\circ}\right.$ to $\left.28^{\circ} \mathrm{N}\right)$, Tibetan Plateau $\left(28^{\circ}\right.$ to $\left.35^{\circ} \mathrm{N}\right)$, and beyond Tibet $\left(35^{\circ}\right.$ to $\left.40^{\circ} \mathrm{N}\right)$

the tropopause temperature is significant near the latitudes of $35^{\circ}$ to $40^{\circ} \mathrm{N}$ in the Tibetan sector in summer of the Northern Hemisphere. Accordingly, the temperature changes over the northern side of Tibet should contain both the effects of obscuration and latitudinal variation in the tropospheric temperature profiles.

Most of the studies analyzed the ground-based observations on the land to examine the eclipse effect on local circulation and weather conditions (Aplin et al. 2016). However, the RO technique sounds the atmosphere 

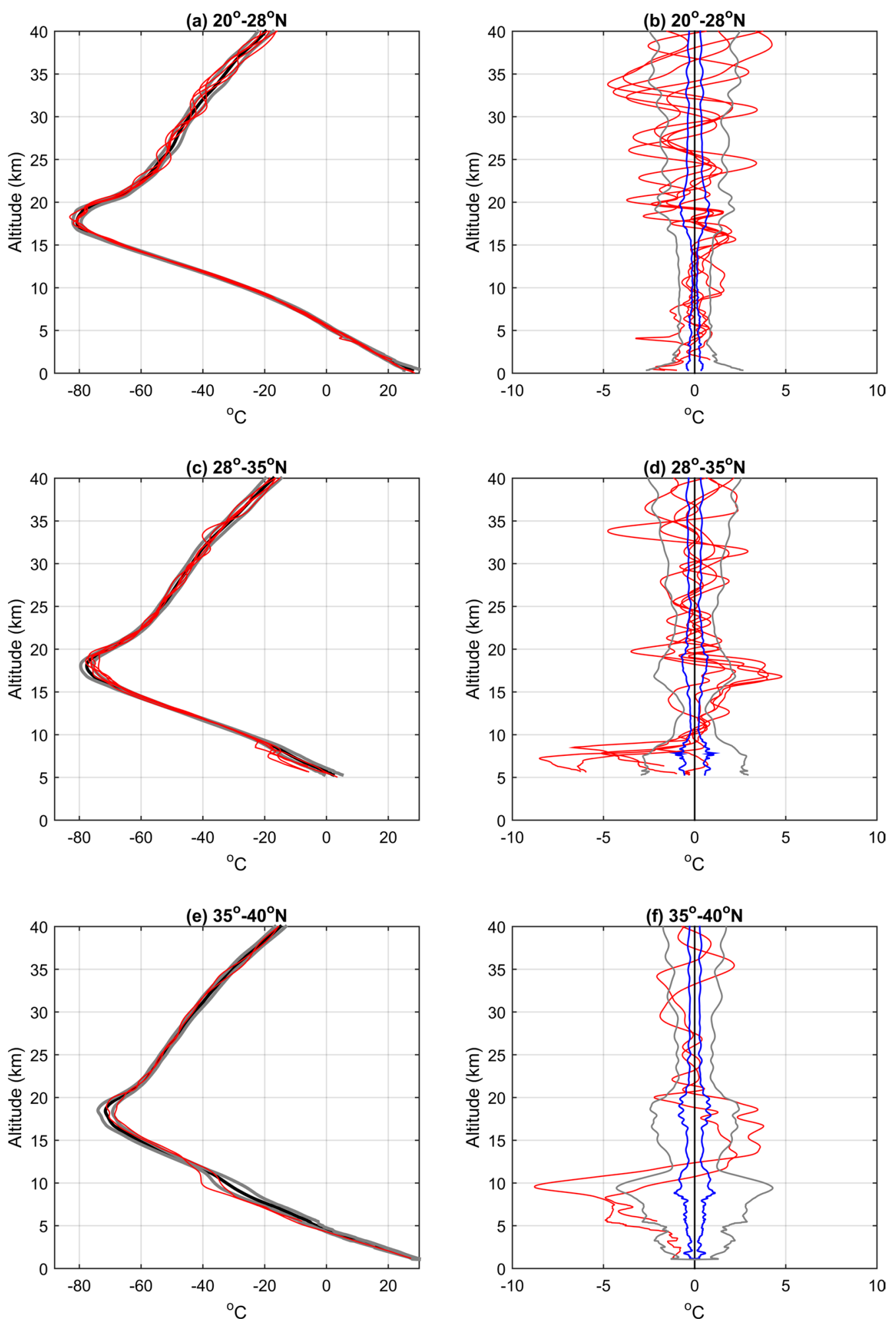

Fig. 2 (Left panels) Comparison of the temperature profiles during the obscuration on 21 June 2020 (red) with the reference profiles (black) in the three areas as shown in Fig. 1. The three areas are (top panels) $20^{\circ}-28^{\circ} \mathrm{N}, 75^{\circ}-100^{\circ} \mathrm{E}$ (North India), (middle panels) $28^{\circ}-35^{\circ} \mathrm{N}, 75^{\circ}-100^{\circ} \mathrm{E}(\mathrm{Tibetan}$ Plateau), and (bottom panels) $35^{\circ}-40^{\circ} \mathrm{N}, 75^{\circ}-100^{\circ} \mathrm{E}$ (beyond Tibet). The reference is the average of the $\mathrm{RO}$ temperatures collected during the period of seven days before and after the eclipse day. 75,48 , and $41 \mathrm{RO}$ soundings were collected for the reference statistics in the areas of $20^{\circ}-28^{\circ} \mathrm{N}$, $28^{\circ}-35^{\circ} \mathrm{N}$, and $35^{\circ}-40^{\circ} \mathrm{N}$, respectively. (Right panels) The difference between the temperature during the eclipse and the reference. The grey and blue curves respectively indicate the standard deviation and $95 \%$ confidence level of the temperatures at each altitude during the 2 weeks 
worldwide, which benefits us to examine the effect over the ocean. Therefore, this study further examined the temperature changes over the Indian Ocean away from the greatest eclipse. Figure $3 \mathrm{a}$ and $\mathrm{b}$ show no obvious response of the temperature to the eclipse over the South India area $\left(10^{\circ}\right.$ to $20^{\circ} \mathrm{N}, 75^{\circ}$ to $\left.100^{\circ} \mathrm{E}\right)$. Nevertheless, in Fig. $3 \mathrm{c}$ and $\mathrm{d}$, the temperature near the tropopause decreases by $\sim 3$ to $5^{\circ} \mathrm{C}$ over the area of Indian Ocean $\left(0^{\circ}\right.$ to $10^{\circ} \mathrm{N}, 75^{\circ}$ to $100^{\circ} \mathrm{E}$ ).

Figure 4 shows the lapse rate profiles over the Tibetan Plateau and the Indian Ocean areas. The lapse rate ranges from -6 to $-9{ }^{\circ} \mathrm{C} / \mathrm{km}$ in the upper troposphere from 10 to $15 \mathrm{~km}$ over Tibet during the eclipse (Fig. 4a). The lapse rate values during the eclipse vary mainly within one standard deviation of the reference values of lapse rate. The lapse rate increases significantly and exceeds the standard deviation above $15 \mathrm{~km}$ altitude. By contrast, over the Indian Ocean area, the lapse rate is lower than one standard deviation of the reference values near $15 \mathrm{~km}$ altitude and drastically increases above it (Fig. 4b). The variations in the lapse rates reveal that the structures and dynamics are different near the tropopause in both the Tibet and Indian Ocean areas during the eclipse.

Figure 5 displays the temporal variations in the temperatures over the areas of Tibetan Plateau and Indian Ocean. Figure $5 \mathrm{a}$ shows the sudden drop in temperature averaged within 5 to $8 \mathrm{~km}$ over the Tibetan Plateau area during the obscuration. The local minimum occurs near the end of the obscuration. On the other hand, the tropopause temperature reaches its maximum near the end (Fig. 5b). By contrast, the tropopause temperature decreases over the Indian Ocean area and reaches the minimum near the end of the eclipse (Fig. 5c).
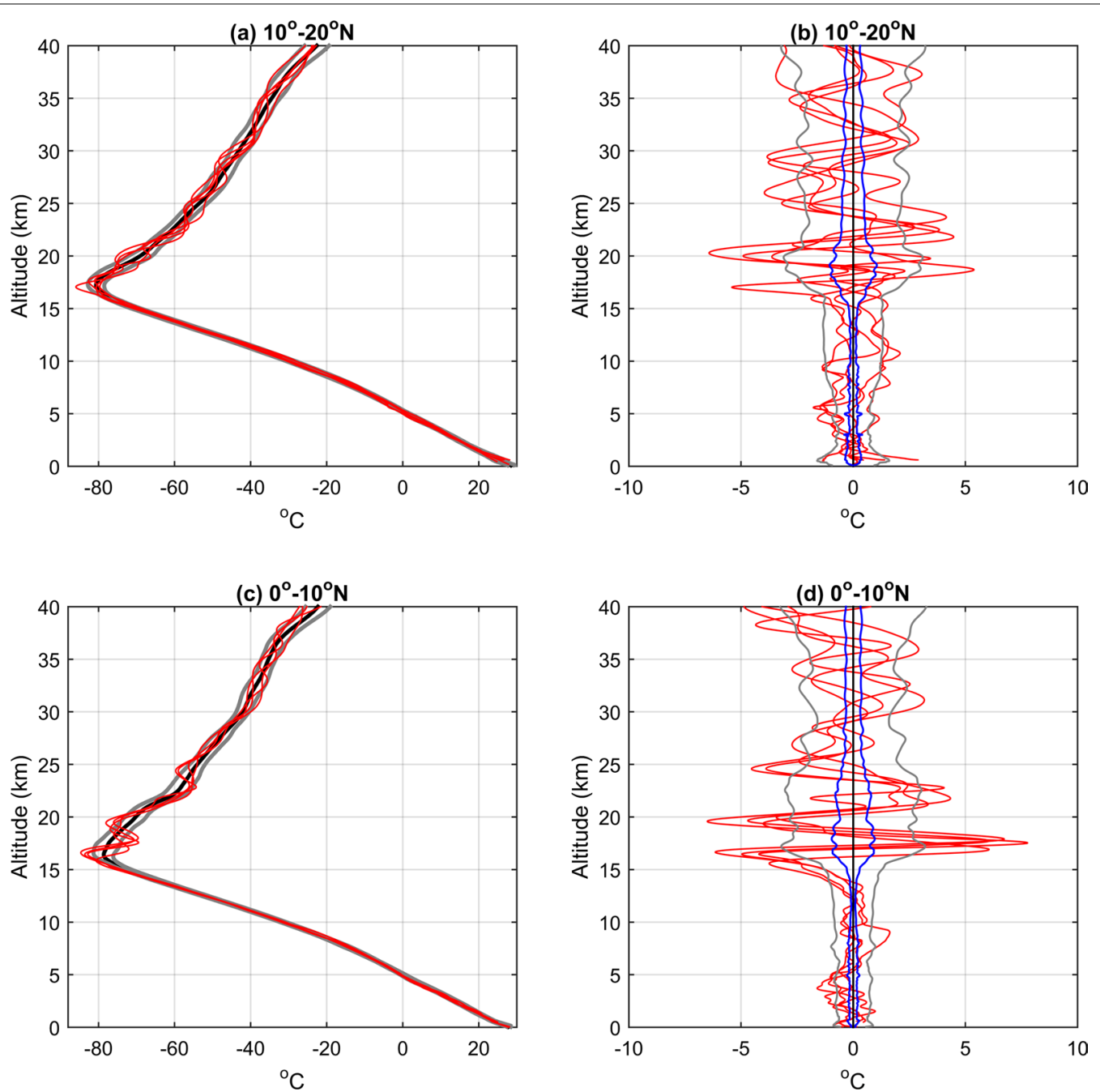

Fig. 3 Same as Fig. 2 but for the temperature profiles over the (Top panels) South India ( $10^{\circ}$ to $20^{\circ} \mathrm{N}, 75^{\circ}-100^{\circ} \mathrm{E}$ ) and (bottom panels) Indian Ocean areas $\left(0^{\circ}\right.$ to $\left.10^{\circ} \mathrm{N}, 75^{\circ}-100^{\circ}\right) .93$ and $118 \mathrm{RO}$ soundings were collected for the reference statistics in the areas of $10^{\circ}-20^{\circ} \mathrm{N}$ and $0^{\circ}-10^{\circ} \mathrm{N}$, respectively 

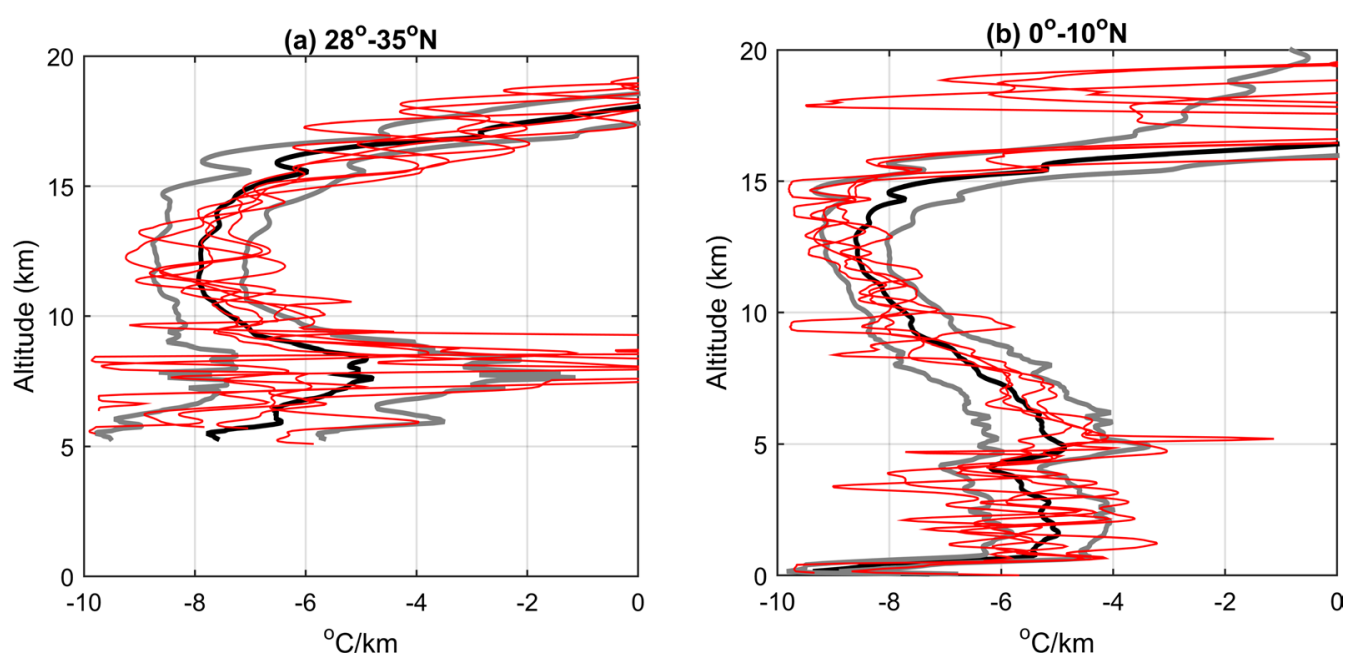

Fig. 4 Lapse rate of the temperature profiles over the areas of $\mathbf{a}$ Tibetan Plateau and $\mathbf{b}$ Indian Ocean (red curves). The black curve is the average of the lapse rates of the $\mathrm{RO}$ temperatures collected during the period of seven days before and after the eclipse day. The grey lines indicate the standard deviation of the lapse rates during the 2 weeks

\section{Discussion}

Wang and Liu (2010) reported that the maximum daily mean difference of the $\mathrm{RO}$ temperature can reach $-6^{\circ} \mathrm{C}$ at $\sim 5-10 \mathrm{~km}$ altitudes within the obscuration path of the 22 July 2009 total solar eclipse. The magnitudes of the temperature decreasing in this study and Wang and Liu (2010) are comparable. The temperature decreased by near $-4^{\circ}$ to $-8^{\circ} \mathrm{C}$ at $\sim 5$ to $8 \mathrm{~km}$ altitudes above the surface of Tibetan Plateau rather than the entire obscuration path during the annular solar eclipse on 21 June 2020. The heat capacity of air over the Tibetan Plateau is smaller than that over India, because the precipitation and humidity over the plateau are much less than those in the surrounding low-elevation region. It would explain why the temperature changes prominently in the lower troposphere over Tibet during the obscuration.

On the other hand, Wang and Liu (2010) showed that the RO temperature increased by $\sim{ }^{\circ} \mathrm{C}$ near the tropopause in the obscuration path during the 2009 total solar eclipse. The tropopause temperature also increases near tropopause above Tibet (Figs. 2 and 5). By contrast, the RO soundings show that the temperature near the tropopause deceases over the Indian Ocean away from the obscuration path.

The classical Hadley circulation, characterized by the air rising from the equator and descending over midlatitudes, is reversed in the summer of the Northern Hemisphere. Heating the Tibetan Plateau (mean altitude of $\sim 5 \mathrm{~km}$ ) due to solar radiation results in the reversed circulation in summer, so-called the Indian monsoon circulation (Webster and Fasullo 2003). The Tibet Plateau is an intense heat source that leads the air rising near and above the plateau and then flowing toward and descending near the equator. The descending flow can suppress the convection over the Indian Ocean in summer (Sun et al. 2014).

The annular solar eclipse occurred on the June solstice of 2020, the beginning of the season of the Indian summer monsoon. The thermal contraction in the lower troposphere induces downward movement in the upper troposphere and lower stratosphere (Wang and Liu 2010). The change of the dynamical process can disturb the convection over the Tibetan Plateau, which further weaken the descending flow and allow the convection to become deeper over the Indian Ocean. Therefore, the tropopause would become colder over the Indian Ocean during and after the obscuration (Figs. 3c, 5c). The obscuration of solar eclipses can induce mesoscale- or synoptic-scale weather conditions (Clayton 1901; Aplin et al. 2016; Eugster et al. 2017; Turner et al. 2018). The results in this study reveal that a solar eclipse may be able to change the monsoon circulation. Utilizing a numerical model analysis in the future can better describe the dynamic process.

It has been speculated that solar eclipses can induce atmospheric gravity waves (AGWs) in the lower atmosphere. The AGWs can propagate upward and generate bow and stern waves (Liu et al. 2011) that consist of plasma density disturbances and sporadic $E$ in the ionosphere near $80 \%$ obscuration over Asia particularly in the Northern Hemispheric summer (Chen et al. 2011; Wang et al. 2021). The stratopause and mesopause with high cooling rates could be the sources of the eclipse-generated AGWs (Brasseur and Solomon 2005). 


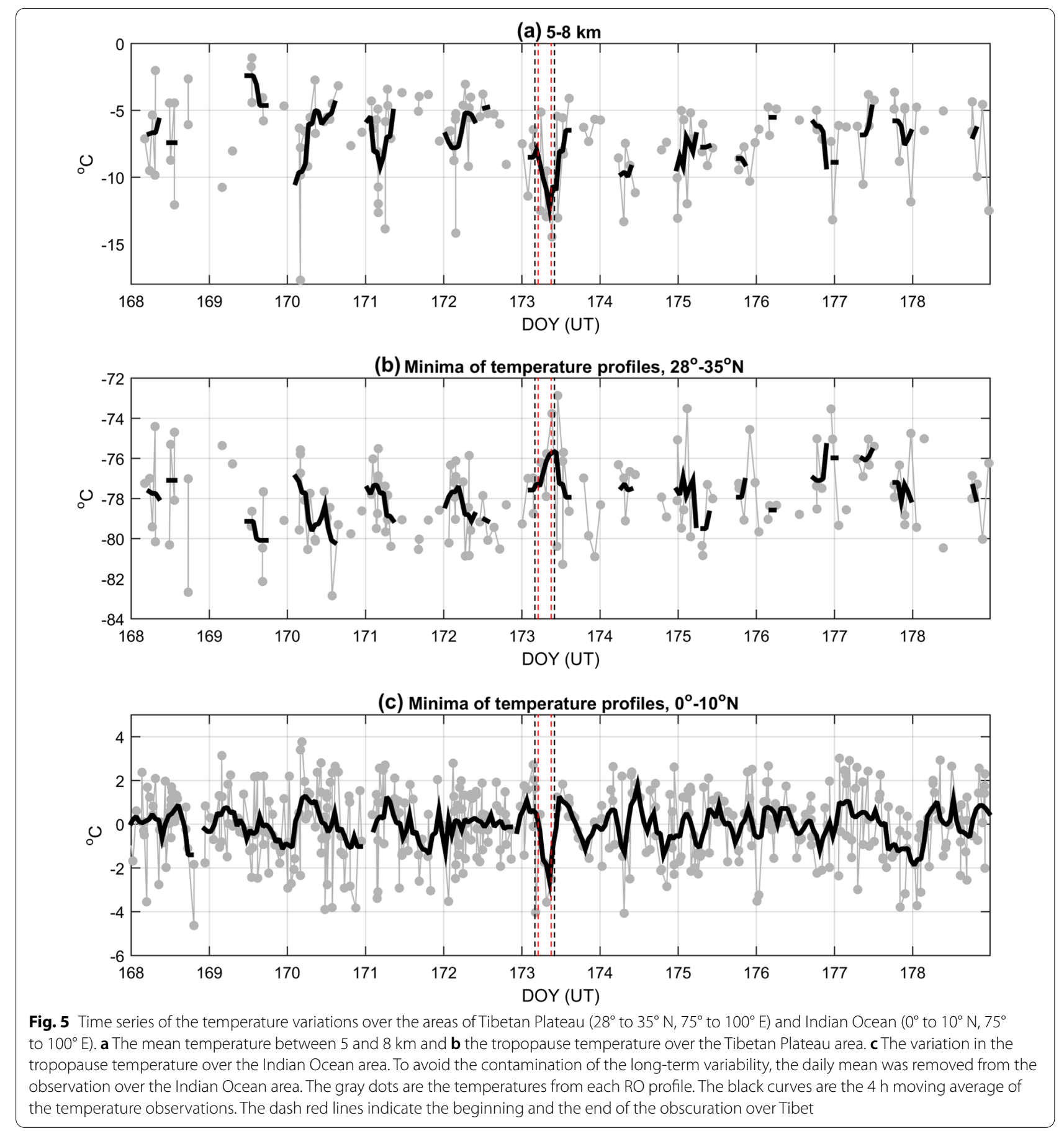

However, the exact origin of the AGWs in the lower atmosphere remains obscure. The prominent changes of the temperature in the troposphere above Tibet suggest that the plateau can be considered as a candidate of the source of the AGWs trigged by the eclipse. The vertical propagation of atmospheric waves from the surface to the ionosphere over and around Tibet can be further examined (Chen et al. 2021a, b).

\section{Conclusion}

The FORMOSAT-7/COSMIC2 (F7/C2) radio occultation (RO) technique vertically scanned the atmosphere during the annular solar eclipse at the summer solstice on 21 June 2020. The moon shadow obscuration provides us a rare and unique chance to depict the response of the lower atmosphere to a space weather phenomenon. The obscuration induced transient temperature changes 
mainly over the Tibetan Plateau area. The thermal contraction of the troposphere appears especially within the $80 \%$ obscuration area over Tibet. The RO observations show that a solar eclipse can not only change weather conditions within the obscuration area, but also possibly disturb the monsoon circulation over Indian Ocean away from the greatest obscuration path.

\section{Acknowledgements}

The authors gratefully acknowledge TACC (ftp://tacc.cwb.gov.tw/) and CDAAC (https://cdaac-www.cosmic.ucar.edu) for providing the FORMOSAT-7/ COSMIC2 radio occultation data. The eclipse information is obtained from https://eclipse.gsfc.nasa.gov. This research is funded by the Joint Funds of the National Natural Science Foundation of China, grant number U2039205, NSFC grants 42174211, 41804154 and 91858205, and the Fundamental Research Funds for the Central Universities, China University of Geosciences (Wuhan), grant number 2018022. The authors would like to thank the reviewers for their comments that help improve this paper.

\section{Authors' contributions}

Y.Y.S. contributed to conceptualization, curation, writing, methodology, and revision; C.H.C. contributed to conceptualization, curation, and revision; T.Y. contributed to discussion and revision; J.W. contributed to discussion and revision; L.Q. contributed to discussion and revision; Y.Q. contributed to data collection and revision; K.L. contributed to discussion and revision. All authors read and approved thefinal manuscript.

\section{Declarations}

\section{Consent for publication}

The authors declare that they have no known competing interests that could have appeared to influence the study reported in this paper.

Received: 2 June 2021 Accepted: 13 January 2022

Published online: 09 February 2022

\section{References}

Aplin KL, Scott CJ, Gray SL (2016) Atmospheric changes from solar eclipses. Phil Trans R Soc A 374:20150217. https://doi.org/10.1098/rsta.2015.0217

Brasseur GP, Solomon S (2005) Aeronomy of the middle atmosphere, chemistry and physics of the stratosphere and mesosphere. Springer, New York

Chen G, Zhao Z, Zhang Y, Yang G, Zhou C, Huang S, Li T, Li N, Sun H (2011) Gravity waves and spread Es observed during the solar eclipse of 22 July 2009. J Geophys Res 116:A09314. https://doi.org/10.1029/2011 JA016720

Chen S-Y, Liu C-Y, Huang C-Y, Hsu S-C, Li H-W, Lin P-H, Cheng J-P, Huang C-Y (2021a) An analysis study of FORMOSAT-7/COSMIC-2 radio occultation data in the troposphere. Remote Sens 13(4):717. https://doi.org/10.3390/ rs13040717

Chen C-H, Sun Y-Y, Lin K et al (2021 b) A new instrumental array in Sichuan, China, to monitor vibrations and perturbations of the lithosphere, atmosphere, and ionosphere. Surv Geophys 42:1425-1442. https://doi.org/10, 1007/s10712-021-09665-1

Clark MR (2016) On the variability of near-surface screen temperature anomalies in the 20 March 2015 solar eclipse. Phil Trans R Soc A 374:20150213. https://doi.org/10.1098/rsta.2015.0213

Clayton HH (1901) Clayton's eclipse cyclone and the diurnal cyclones. Science 13:747-750. https://doi.org/10.1126/science.13.332.747

Eugster W, Emmel C, Wolf S, Buchmann N, McFadden JP, Whiteman CD (2017) Effects of vernal equinox solar eclipse on temperature and wind direction in Switzerland. Atmos Chem Phys 17:14887-14904. https://doi.org/10. 5194/acp-17-14887-2017

Lin C-Y, Lin CC-H, Liu J-Y, Rajesh PK, Matsuo T, Chou M-Y et al (2020) The early results and validation of FORMOSAT-7/COSMIC-2 space weather products: global ionospheric specification and $\mathrm{Ne}$-aided Abel electron density profile. J Geophys Res Space Physics 125:e2020JA028028. https://doi.org/ 10.1029/2020JA028028
Liu JY, Sun YY, Kakinami Y, Chen CH, Lin CH, Tsai HF (2011) Bow and stern waves triggered by the Moon's shadow boat. Geophys Res Lett 38(17):L17109. https://doi.org/10.1029/2011GL048805

Mahmood R, Schargorodski M, Rappin E, Griffin M, Collins P, Knupp K, Quilligan A, Wade R, Cary K, Foster S (2020) The total solar eclipse of 2017: meteorological observations from a statewide mesonet and atmospheric profiling systems. Bull Am Meteorol Soc 101(6):E720-E737. https://doi.org/10. 1175/BAMS-D-19-0051.1

Schreiner WS, Weiss JP, Anthes RA, Braun J, Chu V, Fong J, Hunt D, Kuo Y-H, Meehan T, Serafino W, Sjoberg J, Sokolovskiy S, Talaat E, Wee TK, Zeng Z (2020) COSMIC-2 radio occultation constellation: first results. Geophys Res Lett 47:e2019GL086841. https://doi.org/10.1029/2019GL086841

Sun Y-Y, Liu J-Y, Tsai H-F, Lin C-H, Kou Y-H (2014) The equatorial El Niño-Southern Oscillation signatures observed by FORMOSAT-3/COSMIC from July 2006 to January 2012. Terr Atmos Ocean Sci 25:545-558. https://doi.org/ 10.3319/TAO.2014.02.13.01(A)

Turner DD, Wulfmeyer V, Behrendt A, Bonin TA, Choukulkar A, Newsom RK, Brewer WA, Cook DR (2018) Response of the land-atmosphere system over north-central Oklahoma during the 2017 eclipse. Geophys Res Lett 45:1668-1675. https://doi.org/10.1002/2017GL076908

Wang K-Y, Liu C-H (2010) Profiles of temperature responses to the 22 July 2009 total solar eclipse from FORMOSAT-3/COSMIC constellation. Geophys Res Lett 37:L01804. https://doi.org/10.1029/2009GL040968

Wang K-Y, Liu C-H, Lee L-C, Braesicke P (2012) Observations of stratospheretroposphere coupling during major solar eclipses from FORMOSAT-3/ COSMIC constellation. Space Sci Rev 168(1-4):261-282. https://doi.org/ 10.1007/s11214-011-9829-1

Wang J, Zuo X, Sun YY, Yu T, Wang Y, Qiu L et al (2021) Multilayered sporadicE response to the annular solar eclipse on June 21, 2020. Space Weather 19:e2020SW002643. https://doi.org/10.1029/2020SW002643

Webster PJ, Fasullo J (2003) Monsoon: dynamical theory. In: Holton J, Curry JA, Pyle JA (eds) Encyclopedia of atmospheric sciences. Elsevier, New York, pp 1370-1386

\section{Publisher's Note}

Springer Nature remains neutral with regard to jurisdictional claims in published maps and institutional affiliations.

\section{Submit your manuscript to a SpringerOpen ${ }^{\circ}$ journal and benefit from:}

- Convenient online submission

- Rigorous peer review

- Open access: articles freely available online

- High visibility within the field

- Retaining the copyright to your article

Submit your next manuscript at $\boldsymbol{\nabla}$ springeropen.com 